\title{
Effect of Trace Water on the Film Formation on Nickel Anode
}

\author{
Akimasa TASAKA*, Yoshihiro TSUKUDA, Toshitaka OHASHI, \\ Shinji YAMADA, Kazuhiko MATSUSHITA, Akiko KOHMURA, \\ Nobuhiro MURAMATSU and Hitoshi TAKEBAYASHI
}

Received June 2, 1997 ; Accepted August 5, 1997

\begin{abstract}
The effects of trace water in $\mathrm{NH}_{4} \mathrm{~F} \cdot 2 \mathrm{HF}$ melt at $100{ }^{\circ} \mathrm{C}$ on the formation rate and the physico-chemical properties of oxidized layer on the $\mathrm{Ni}$ anode were studied. The potentiodynamic and potentiostatic polarization behaviors of the $\mathrm{Ni}$ anode were investigated to elucidate the anodic processes. The overall anodic current and the current loss caused by nickel dissolution at the potential range higher than $4.75 \mathrm{~V}$ were decreased by a trace of water in the melt, presumably due to the formation of dense oxide layer.
\end{abstract}

\section{INTRODUCTION}

A large amount of gaseous fluorine compounds such as nitrogen trifluoride $\left(\mathrm{NF}_{3}\right)$, sulphur hexafluoride $\left(\mathrm{SF}_{6}\right)$, and tungsten hexafluoride $\left(\mathrm{WF}_{6}\right)$ are consumed by the electronics industry in Japan. Pure $\mathrm{NF}_{3}$ free from $\mathrm{CF}_{4}$ can be obtained by the electrolysis of $\mathrm{NH}_{4} \mathrm{~F} \cdot 2 \mathrm{HF}$ with the nickel anode to meet such demand. However, corrosion of the anode is a trouble, which corresponds to the current losses of $3 \sim 5 \%$. Deposition of $\mathrm{NiF}_{2}$ and $\mathrm{NH}_{4} \mathrm{NiF}_{3}$ on the anode surface and the cell bottom is another problem. According to the previous work, ${ }^{1)}$ the nickel dissolution is diminished by a trace of water in the melt whereas the current efficiency for $\mathrm{NF}_{3}$ formation decreases. The surface oxide on the anode formed in a molten salt containing water was thick and its oxygen content was high. ${ }^{2)}$ Analysis of the oxide layer on the nickel anode formed in $\mathrm{NH}_{4} \mathrm{~F} \cdot 2 \mathrm{HF}$ melt may lead to the development of a metallic anode having the resistance to corrosion in a fluoride melt.

This paper deals with the effect of trace water in a molten $\mathrm{NH}_{4} \mathrm{~F} \cdot 2 \mathrm{HF}$ on the characteristics and the surface morphology of the oxide layer on the nickel anode.

\section{EXPERIMENTAL}

A box-type polytetrafluoroethylene (PTFE) cell of $0.5 \mathrm{dm}^{3}$ in volume was provided for the electrochemical and corrosion experiments. A nickel

Doshisha University, Faculty of Engineering, Department of Molecular Science and Technology (Miyako-dani, 1-3, Tadara, Kyotanabe, Kyoto, 610-03, Japan)

Key Words : Electrochemical Fluorination, Effect of Water, Oxide Layer, Nickel Anode, Corrosion.
(99.999\%) wire of $0.07 \mathrm{~cm}^{2}$ effective area and a sheet of $0.5 \sim 2.0 \mathrm{~cm}^{2}$ were employed as the anode. The counter cathode was a large nickel sheet. A Ni $/ \mathrm{NiF}_{2}$ electrode was employed as reference, ${ }^{2)}$ whereas the potentials in this paper were converted to the hydrogen electrode scale. This cell was positioned in a dry nitrogen chamber at $100^{\circ} \mathrm{C}$ to remove moisture from the atmosphere during experiment. ${ }^{1)}$

$\mathrm{NH}_{4} \mathrm{~F} \cdot 2 \mathrm{HF}$ was prepared with extra pure $\mathrm{HF}(99.99 \%)$ and $\mathrm{NH}_{4} \mathrm{~F}(99.9 \%)$ in a dry box. Since these chemicals contained a little water, preelectrolysis was conducted with a carbon anode at a low current density for about ten days to reduce the water content to less than $0.02 \mathrm{wt} \%$ prior to electrochemical, corrosion, SEM, and XPS studies. ${ }^{3,4)}$

Potentiostatic electrolysis in the range of $2 \sim 7$ $V$ vs. $\mathrm{H}_{2}$ was conducted at $100{ }^{\circ} \mathrm{C}$ for 2 hours, and the anode was washed with $47 \% \mathrm{HF}$ aqueous solution to remove adhesive electrolyte before inspecting by XPS and SEM. ESCA-1000 (Shimadzu Seisakusho Ltd.) with an Al-K $\alpha$ radiator (1400 eV) was used for the XPS-analysis., ${ }^{1,2)}$ The nickel surface was etched with an argon beam in a spectrometer (Shimadzu).

For testing the corrosion behavior of nickel anode in $\mathrm{NH}_{4} \mathrm{~F} \cdot 2 \mathrm{HF}$ with and without preelectrolysis, the $\mathrm{Ni}$ specimen was potentiostatically polarized in the range of $0.5 \sim 6.0 \mathrm{~V}$ vs. $\mathrm{H}_{2}$. Temperature of the electrolyte was kept constant at 100 ${ }^{\circ} \mathrm{C}$. The specimen was washed with fresh water and methanol before weighing. The corrosion rate and the corresponding current losses caused by $\mathrm{Ni}$ dissolution with an assumption of a two-electron transfer for the reaction (1): 


$$
\mathrm{Ni} \longrightarrow \mathrm{Ni}^{2+}+2 \mathrm{e}^{-}
$$

were evaluated from the weight loss.

\section{RESULTS AND DISCUSSION}

In a dehydrated melt, a virgin $\mathrm{Ni}$ anode was dissolved in the potential range of $0.3 \sim 0.5 \mathrm{~V}$ and passivated in the range of $1 \sim 4 \mathrm{~V}$ as curve 1 in Fig. 1. The current density was increased gradually with sweeping potential from $4 \mathrm{~V}$ to $6 \mathrm{~V}$, probably caused by the fluorination of nickel. The current density increased largely, when gas was liberated at potentials higher than $6 \mathrm{~V}$.

The potential sweep measurement with the same specimen was repeated in the potential range of $0 \mathrm{~V}$ to about $8 \mathrm{~V}$. Curve 2 shows the second run, which differs from curve 1 . The peak caused by the active dissolution of $\mathrm{Ni}$ at $0.3 \mathrm{~V}$ disappeared, because the protective layer, composed of oxide and/ or fluoride, formed in the potential range higher than $4 \mathrm{~V}$ during the first run. No current passed at potentials lower than $4 \mathrm{~V}$, but the current was increased thereafter and became a limited value, 300 $\mathrm{mA} / \mathrm{cm}^{2}$, at $5 \mathrm{~V}$. The current density was increased again at the potentials higher than $6 \mathrm{~V}$, but was lower than the first run. A stagnation of current density at $7 \mathrm{~V}$ and further increase at higher potentials may suggest the occurrence of any parallel reaction. In fact, ammonium ion is fluorinated in the potential range higher than $4 \mathrm{~V}$, or Regions III and IV in the figure. Curve 3 represents the 50 th run, which is almost the same as of the second run,

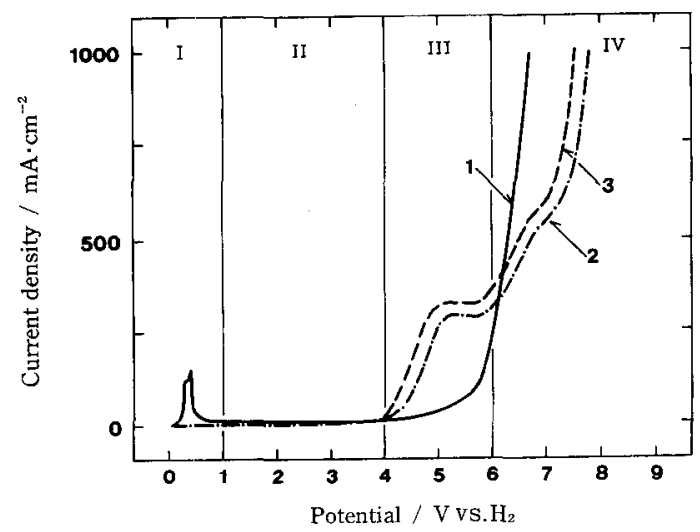

Fig. 1 Anodic polarization curves of nickel in a dehydrated $\mathrm{NH}_{4} \mathrm{~F} \cdot 2 \mathrm{HF}$ melt at $100^{\circ} \mathrm{C}$ by the potential sweep method. Curve $1 ; 1$ st run, Curve $2 ; 2$ nd run, Curve $3 ; 50$ th run. whereas the current density becomes a little larger in Regions III and IV, probably due to rough surface after repetitive experiment.

The polarization curves obtained in a molten salt containing a trace of water differed extensively from that in anhydrous medium as shown in Fig. 2. In the first run, the nickel anode was dissolved at $0.3 \mathrm{~V}$ then passivated in Region II. The current density was increased to some extent in Region III, but was a limited value, ca. $200 \mathrm{~mA} / \mathrm{cm}^{2}$, even if the potential was as high as $8 \mathrm{~V}$, presumably caused by the formation of thick oxide. With repeating potential sweep, no current flowed in the potential range lower than $6 \mathrm{~V}$. At higher potentials, gas evolved on the anode, and the electrolytic current increased. From these experiments, it becomes evident that a trace of water in the melt passivates the nickel anode and retards the fluorination reaction of ammonium ions.

The corrosion rate was examined with fresh $\mathrm{Ni}$ specimens under potentiostatic conditions. In dehydrated melt, $\mathrm{Ni}$ was actively dissolved at $0.5 \mathrm{~V}$ as shown in Table 1, but passivated perfectly in the potential range of $1 \sim 4 \mathrm{~V}$. Ni was dissolved again but its amperage was less than $10 \%$ of the total current passed. The fluorination reaction of ammonium ion took place at the potentials higher than ca. $4 \mathrm{~V}$ as stated before. At the potentials higher than $4.75 \mathrm{~V}$, the Ni corrosion was stimulated, but was almost proportional to the overall current density. Then the current inefficiency caused by $\mathrm{Ni}$

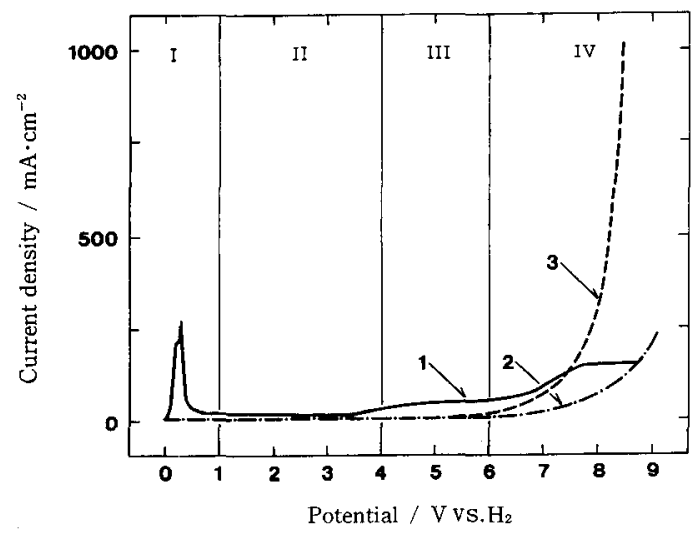

Fig. 2 Anodic polarization curves of nickel in a dehydrated $\mathrm{NH}_{4} \mathrm{~F} \cdot 2 \mathrm{HF}$ melt at $100^{\circ} \mathrm{C}$ by the potential sweep method. Curve $1 ; 1$ st run, Curve $2 ; 2$ nd run, Curve $3 ; 50$ th run. 
corrosion was unchanged (see the last column in Table 1).

In hydrated electrolyte, on the other hand, the Ni substrate was dissolved through the oxide layer in the potential range of $4.5 \sim 6.0 \mathrm{~V}$, but the corrosion rate was low compared with anhydrous electrolyte because of the thick and nonconductive surface oxide. The oxide layer may contribute the protection of $\mathrm{Ni}$ from corrosion, but it retards the fluorination reaction as well.

Figure 3 shows the chronopotentiograms of a fresh nickel anode at $25 \mathrm{~mA} / \mathrm{cm}^{2}$ and at $100{ }^{\circ} \mathrm{C}$ in dehydrated and hydrated melts. In a dehydrated melt (Fig. 3-a), the anode potential jumped to ca. 6 $\mathrm{V}$ vs. $\mathrm{H}_{2}$ at 3 minutes after switch-on, then dropped to ca. $4.7 \mathrm{~V}$. The potential fluctuated extensively after 10 minutes elapsed, probably caused by repetitive degradation and regeneration of the oxide layer on the $\mathrm{Ni}$ anode. ${ }^{5,6)}$ The chronopotentiogram in a hydrated electrolyte (Fig. 3-b) was almost the same as in a dehydrated melt while the potential was fairly stable.

The SEM photographs of the surface of nickel anode polarized at $5.0 \mathrm{~V}$ for 120 minutes in dehydrated and hydrated $\mathrm{NH}_{4} \mathrm{~F} \cdot 2 \mathrm{HF}$ are shown in Fig. 4.
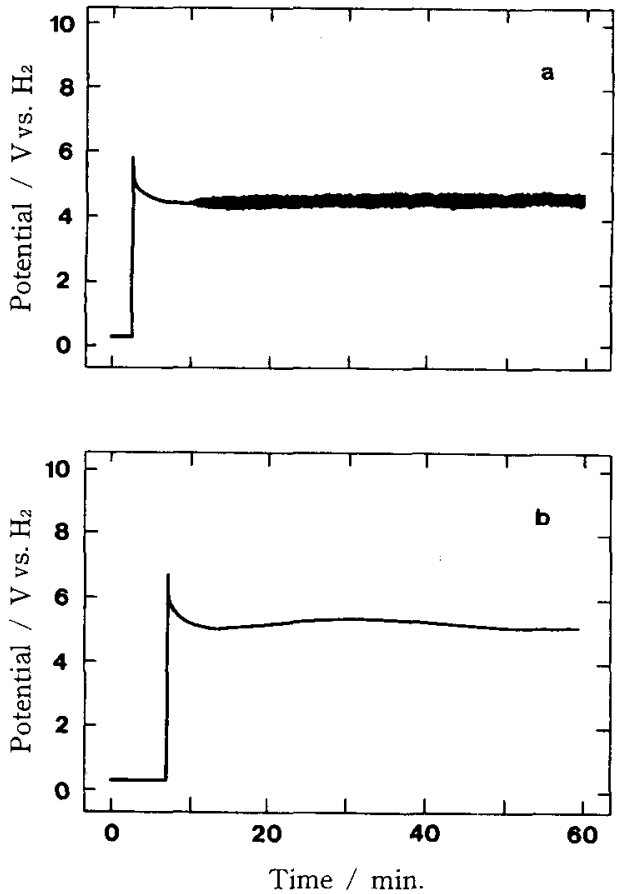

Fig .3 Chronopotentiograms of a nickel anode at $25 \mathrm{~mA}$ / $\mathrm{cm}^{2}$ in molten $\mathrm{NH}_{4} \mathrm{~F} \cdot 2 \mathrm{HF}$ melt at $100^{\circ} \mathrm{C}$. (a) dehydrated melt, (b) hydrated melt.

Table 1 Weight losses of a nickel anode under given potentials in $\mathrm{NH}_{4} \mathrm{~F} \cdot 2 \mathrm{HF}$ melt at $100^{\circ} \mathrm{C}$.

\begin{tabular}{ccccc}
\hline Anode potential & $\begin{array}{c}\text { Duration of } \\
\text { electrolysis } \\
\text { (minutes) }\end{array}$ & $\begin{array}{c}\text { Average } \\
\text { current density } \\
\left(\mathrm{mA} / \mathrm{cm}^{2}\right)\end{array}$ & $\begin{array}{c}\text { Corrosion rate } \\
\left(\mathrm{mg} / \mathrm{cm}^{2} / \mathrm{h}^{1}\right)\end{array}$ & $\begin{array}{c}\text { Current losses caused by } \\
\text { Ni dissolution }\left(Q_{\mathrm{a}} / Q_{\mathrm{t}}\right)\end{array}$ \\
\hline $\begin{array}{c}\text { Dehydrated melt } \\
0.5\end{array}$ & 60 & 3.88 & 4.26 & 100.4 \\
1.0 & 60 & 0.00 & 0.00 & 0.00 \\
2.0 & 60 & 0.00 & 0.00 & 0.00 \\
3.0 & 60 & 0.04 & 0.00 & 0.00 \\
4.0 & 60 & 0.23 & 0.00 & 0.00 \\
4.5 & 60 & 0.85 & 0.10 & 10.8 \\
4.75 & 60 & 23.3 & 0.90 & 3.54 \\
5.0 & 60 & 85.1 & 3.60 & 3.87 \\
6.0 & 60 & 451.8 & 15.8 & 3.18 \\
\hline Hydrated melt & & & & 100.0 \\
0.5 & 60 & 3.99 & 4.35 & 0.00 \\
1.0 & 60 & 0.00 & 0.00 & 0.00 \\
2.0 & 60 & 0.00 & 0.00 & 0.00 \\
3.0 & 60 & 0.04 & 0.00 & 6.09 \\
4.0 & 60 & 0.80 & 0.053 & 4.46 \\
4.5 & 60 & 0.85 & 0.043 & 1.00 \\
4.75 & 60 & 5.65 & 0.20 & 1.09 \\
5.0 & 60 & 13.7 & 0.15 & \\
6.0 & 60 & 104.5 & 1.25 & \\
\hline
\end{tabular}




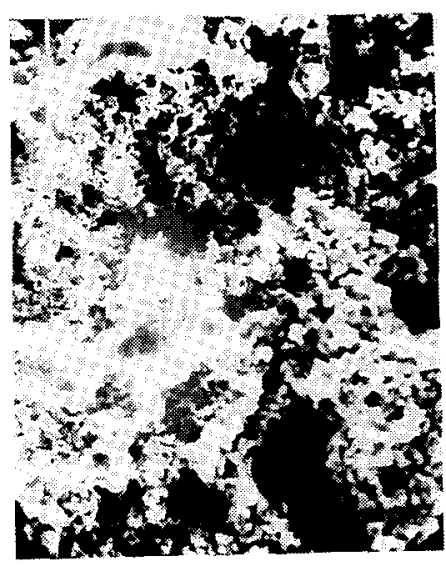

a Dehydrated melt

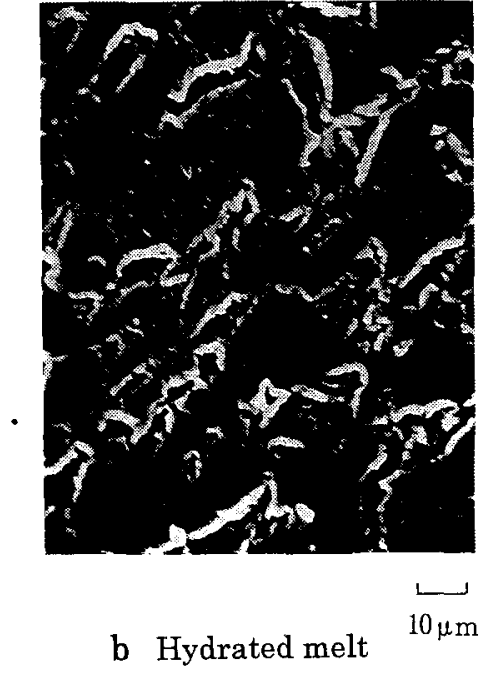

Fig. 4 SEM photographs of the anode surface polarized at $5.0 \mathrm{~V}$ vs. $\mathrm{H}_{2}$ for 120 minutes in $\mathrm{NH}_{4} \mathrm{~F} \cdot 2 \mathrm{HF}$ melt at $100{ }^{\circ} \mathrm{C}$. (a) dehydrated melt, (b) hydrated melt.

The nickel anode polarized in hydrated electrolyte was covered with relatively tight layer having many defects, while the specimen treated with dehydrated electrolyte was coated with loose deposit having a number of crevices and pores.

The chemical composition of the surface layer was examined by XPS. The ordinate of Fig. 5 is the intensity ratio of $F$ to $O$, and the abscissa is the bombardment time which corresponds to the depth from the surface. The $\mathrm{Ni}$ anode was passivated and very small current flowed to maintain the passive film at $2 \mathrm{~V}$. Since no significant current for fluorination reaction was observed, the $\mathrm{F}$ content in the outside layer was almost the same as in the bulk (circular points). At $5 \mathrm{~V}$, on the other hand, the fluorination of $\mathrm{NH}_{4}{ }^{+}$in dehydrated melt proceeded on the oxidized Ni surface which repeatedly degraded and regenerated under high potentials (rectangular points). It causes the contamination of the oxidized layer with F species. The XPS spectrum indicates very high content of $F$ in the outside surface of $\mathrm{Ni}$ anode in anhydrous electrolyte. The oxidation of $\mathrm{Ni}$ was stimulated at high potentials, such as at $7 \mathrm{~V}$, and it resulted the decrease of the $\mathrm{F} / \mathrm{O}$ ratio (triangular points).

On the other hand, the $\mathrm{Ni}$ anode was oxidized preferentially and covered with tight and thick oxide layer, when it was electrolyzed in the hydrated melt. The current density was low enen at high

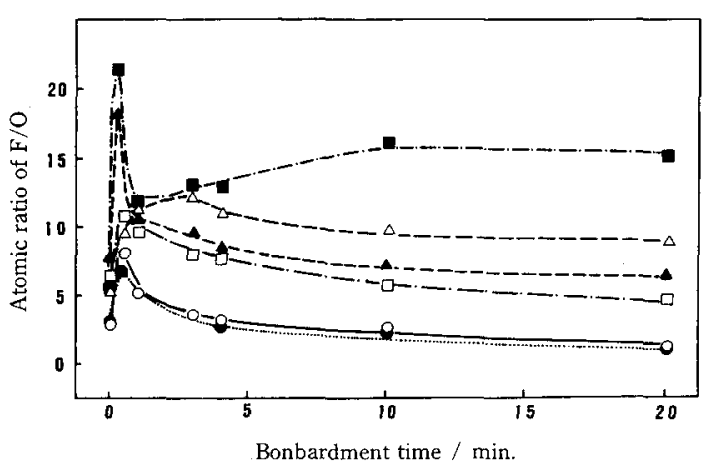

Fig. 5 Depth profiles of the oxide layer on the nickel anode polarized at $2.0 \mathrm{~V}(\bigcirc, \mathrm{O}), 5.0 \mathrm{~V}(\square, \square)$, and 7.0 V vs. $\mathrm{H}_{2}(\triangle, \Delta)$ in molten $\mathrm{NH}_{4} \mathrm{~F} \cdot 2 \mathrm{HF}$ melt at 100 ${ }^{\circ} \mathrm{C}$ for 120 minutes. $\bigcirc, \square, \triangle$ : hydrated, $\bigcirc, \boldsymbol{\square}, \boldsymbol{\Delta}$ : dehydrated.

potentials because of high resistance of the surface layer as shown in Fig. 2. Therefore, the F content in the surface layer formed in the hydrated melt is low over the entire ranges of potential and depth examined.

Figure 6 shows the results of the XPS analysis of the $\mathrm{Ni}$ anode polarized in dehydrated and hydrated melts for 2 hours. The ordinate is the ratio of peak height of $\mathrm{Ni}$ at $852.9 \mathrm{eV}$ to that of nickel fluoride at $857.7 \mathrm{eV}$, and the abscissa is the same as that of Fig. 5. The relative height of metallic nickel at the surface is close to zero in all cases, represen- 
ting fully fluorinated. The relative intensity of the specimen polarized at $2 \mathrm{~V}$ increased quickly with the bombardment time and was almost independent of the water content in the melt (circular points). Although the surface layer formed in the passive region is thin as mentioned in Figs. 1 and 2, it becomes thick when $\mathrm{Ni}$ is polarized at the potentials higher than $5 \mathrm{~V}$ vs. $\mathrm{H}_{2}$. The current density for $\mathrm{Ni}$ oxidation depends on the water content in the melt and the operating conditions. These factors may cause difference of the intensity vs. time curve in hydrated melt (Open, rectangular) from that in dehydrated melt (Closed, rectangular).

The electrical conductivity of the surface layer on the $\mathrm{Ni}$ anode varies with the chemical composition and the morphology, i.e., the higher the oxide content the higher is the conductivity. Therefore, the surface layer on the $\mathrm{Ni}$ specimen polarized in hydrated melt would be more conductive than that treated in dehydrated melt because the oxide content is high. However, the third column in Table 1 shows that the overall current density in the potential range higher than $4.75 \mathrm{~V}$ in dehydrated melt is larger than that in a hydrated melt, probably due to a difference of morphology of the surface layer as observed in Fig. 4. The surface layer formed in dehydrated melt is rough and thin with many holes and crevices, and hence the molten electrolyte can penetrate easily toward the layer, resulting in large current density. Also, it

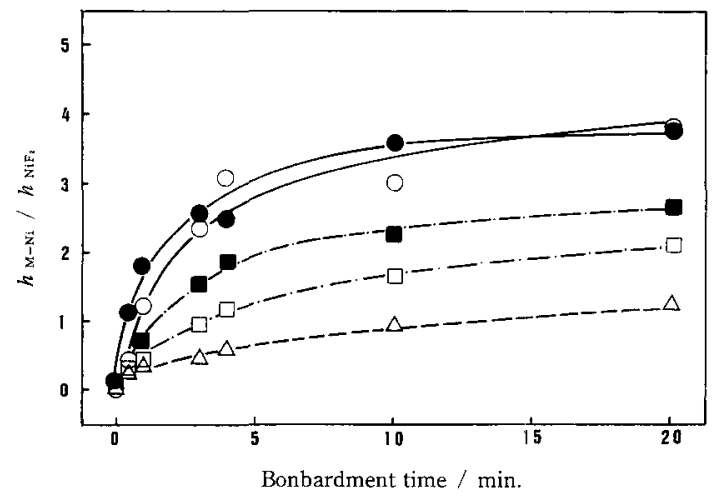

Fig. 6 Intensity ratio of $\mathrm{Ni}$ to $\mathrm{NiF}_{2}$ of the specimens polarized at $2.0 \mathrm{~V}(\mathrm{O}, \mathrm{O}), 5.0 \mathrm{~V}(\square, \square)$, and $7.0 \mathrm{~V}$ vs. $\mathrm{H}_{2}$ $(\triangle)$ in $\mathrm{NH}_{4} \mathrm{~F} \cdot 2 \mathrm{HF}$ melt at $100{ }^{\circ} \mathrm{C}$ for 120 minutes. $\mathrm{O}$, $\square, \triangle$ : hydrated, $\mathbf{O}$ : dehydrated. causes relatively high rate of corrosion of the $\mathrm{Ni}$ anode compared to that in hydrated melt as shown in Table 1.

\section{CONCLUSION}

The effect of water on the corrosion of $\mathrm{Ni}$ anode polarized in $\mathrm{NH}_{4} \mathrm{~F} \cdot 2 \mathrm{HF}$ melt in the potential range of 0 to $8 \mathrm{~V}$ vs. $\mathrm{H}_{2}$ was studied. At low potentials close to the static potential of $\mathrm{Ni}$ immersed in the melt, Ni was actively dissolved when the potential was moved to the positive direction, while it was no longer attacked by active dissolution when it was polarized at high potentials. Nickel was passivated at the potentials in the range of $1 \sim 4 \mathrm{~V}$. Gas evolved from the anode when the potential was increased beyond ca. $6 \mathrm{~V}$.

According to the corrosion experiments, the current losses due to $\mathrm{Ni}$ dissolution was rather decreased from the maximum value at $4.75 \mathrm{~V}$ vs. $\mathrm{H}_{2}$, when the potential was incresed, especially in hydrated melt. It is probably due to the formation of protective film composed of $\mathrm{NiF}_{2}$ and $\mathrm{NiO}_{2}$ on the $\mathrm{Ni}$ anode. The corrosion rate in dehydrated melt was larger than that in hydrated melt because the surface layer was relatively rough and thin.

Special thanks are due to Dr. Fumio Hine, Professor Emeritus of Nagoya Institude of Technology, for his fruitful discussion. The authors wish to express many thanks to Morita Chemical Industry Co. Ltd., for supplying chemicals.

\section{References}

1) A. Tasaka, H. Kobayashi, M. Negami, M. Hori, T. Osada, K. Nagasaki, T. Ozaki, H. Nakayama and K. Katamura, J. Electrochem. Soc, 144192 (1997).

2) A. Tasaka, K. Miki, T. Ohashi, S.-I. Yamaguchi, M. Kanemaru, N. Iwanaga and M. Aritsuka, J. Electrochem. Soc., 141, 1460 (1994).

3) T. Nakajima, T. Ogawa and N. Watanabe, J. Electrochem. Soc., 134, 8 (1987).

4) A. Tasaka, M. Hori, T. Harada, H. Inoue and M. Ohashi, Sci. \& Engng. Rev. Doshisha Univ., 34, 153 (1993).

5) A. Tasaka, K. Mizuno, A. Kamata and K. Miki, J. Fluorine Chem., 57, 121 (1992).

6) A. Tasaka, T. Osada and T. Kawagoe, Proceedings Volume 96-7, p. 144 (1996), Electrochem. Soc.; A. Tasaka, T. Kawagoe, A. Takuwa, M. Yamanaka, T. Tojo and $\mathbf{M}$. Aritsuka, Submitted to J. Electrochem. Soc. 